\title{
TERRITÓRIO, DESENVOLVIMENTO E ASSOCIATIVISMO: UMA ANÁLISE SOBRE A REGIÃO DO DOURO, PORTUGAL ${ }^{1}$
}

\author{
TERRITORY, DEVELOPMENT AND ASSOCIATIVISM: AN ANALYSIS OF THE DOURO REGION, PORTUGAL
}

\section{RESUMO}

O território é formado por um conjunto de elementos, iniciativas e relações que marcam a relação sociedade e natureza. Nesse sentido, existem diversos territórios, entre eles os territórios vitícolas, cuja vinha e vinho são os pontos centrais da articulação territorial. No território do Vinho do Douro, Região Demarcada do Douro, norte de Portugal, a vitivinicultura faz parte da história, paisagem, cultura e economia. Porém, para a manutenção do desenvolvimento local deste território são realizadas ações coletivas, que atuam na valorização local, no fortalecimento do turismo, especialmente ligado ao vinho, na inovação vitivinícola e na criação de novas oportunidades comerciais para os produtos locais. Assim sendo, este trabalhodiscorre sobre o território e o desenvolvimento rural,abordando especificamente o papel das associações atuantes no Território do Douro em busca do desenvolvimento local.

Palavras-chave: Território; Região do Douro; Portugal; Desenvolvimento local; Ações coletivas.

\section{ABSTRACT}

The territory is formed by a set of elements, initiatives and relations that mark the relation society and nature. In this sense, there are several territories, among them the wine-growing territories, whose vineyard and wine are the central points of the territorial articulation. In the territory of Douro Wine, Douro Demarcated Region, northern Portugal, winemaking is part of history, landscape, culture and economy. However, in order to maintain the local development of this territory, collective actions are carried out, focusing on local valorization, strengthening tourism, especially wine, wine innovation and creating new commercial opportunities for local products. Thus, this paper discusses the territory and rural development, specifically addressing the role of associations working in the Douro Territory in search of local development.

Keywords: Territory; Douro Region; Portugal; Local development; Collective actions.

\author{
Vanessa Manfio ${ }^{a}$ \\ Rosa Maria Vieira Medeiros ${ }^{a}$ \\ Artur Cristóvão ${ }^{b}$ \\ ${ }^{a}$ Universidade Federal do Rio Grande do \\ Sul (UFRGS), Porto Alegre, RS, Brasil \\ ${ }^{\text {b }}$ Universidade de Trás-os-Montes e Alto \\ Douro (UTAD), Vila Real, Portugal
}

DOI: $10.12957 /$ geouerj.2020.35802

Correpondência: nessamanfio@gmail.com

Recebido em: 6 jul. 2018

Aceito em: 5 fev.2020

1 O presente trabalho foi realizado com financiamento da CAPES, Coordenação de Aperfeiçoamento de Pessoal de Nível Superior Brasil, através do Programa Doutorado Sanduíche no Exterior - PDSE, no período de abril a julho de 2017 e apoio da Universidade de Trás-os-Montes e Alto Douro (UTAD). 


\section{INTRODUÇÃO}

O território é formado através da dinâmica de um grupo social que exerce uma série de relações e ações e que articula seu poder e identidade na reprodução espacial. O território é social e por isso evidenciam-se sobre ele ações coletivas. Estas são importantes, pois a articulação dos atores locais na organização de iniciativas garante a consolidação e desenvolvimento territorial.

Dessa forma, este artigo propõe-se refletir sobre o conceito de território, buscando dialogar a respeito do desenvolvimento rural, partindo da dinâmica de associações, a fim de proporcionar novas atividades e estruturas para atender à necessidade dos atores locais e da comunidade em geral.

A área da pesquisa centra-se na Região Demarcada do Douro, especificamente na atuação de várias organizações que tem objetivos diferentes, mas que são importantes para o contexto local, nomeadamente: Associação Douro Histórico, Douro Superior - Associação de Desenvolvimento (Associação Douro Superior), Beira Douro - Associação de Desenvolvimento do Vale do Douro (Associação Beira do Douro), Associação para o Desenvolvimento da Viticultura Duriense (ADVID), Associação dos Empresários Turísticos do Douro e Trásos-Montes (AETUR) e Douro Generation - Associação de Desenvolvimento (Douro Generation).

Para cumprir com a proposta de estudos desta pesquisa utilizamos a abordagem qualitativa, com a aplicação de entrevistas semiestruturadas, conversas informais, análise de literaturas e na coleta de materiais a campo. Assim, a pesquisa contribuirá com os estudos geográficos sobre o Douro, obtendo novos subsídios para entender o papel das associações no desenvolvimento rural e local.

\section{$\mathrm{O}$ associativismo como agente de desenvolvimento do território}

O território é formado por várias relações (econômicas, culturais, políticas, ideológicas e sociais) que integram a identidade, o poder e a construção física territorial. Para Haesbaert (2008), o território nasce de uma dupla conotação material e simbólica, tendo a ver com dominação e identificação, a partir da apropriação sociedade - espaço.

Em Pinto (2011, p. 14), “O território implica a existência de uma identidade, uma ligação a um determinado local que é partilhada pelos indivíduos que pertencem a esse mesmo local, num sentimento de propriedade ou de posse".

Porém, o território é complexo como afirma Saquet (2004, p.144),

O território é natureza e sociedade simultaneamente, é economia, política e cultura, ideia e matéria, fixos e fluxos, enraizamento, conexão e redes, domínio e subordinação, degradação e proteção ambiental, é local e global e singular e universal concomitantemente, terra, formas espaciais e relações de poder $[\ldots . .$.$] .$ 
No caso dos territórios rurais, Veiga (2005) coloca que eles apresentam especificidades próprias que resultam da sua história, das relações, da densidade demográfica e do tipo de povoamento ou aglomerado. Estas especificidades são importantes para entender as transformações territoriais (VEIGA, 2005).O rural é alvo de múltiplas intervenções de desenvolvimento em que se cruzam atores públicos, privados, coletivos e individuais (CRISTÓVÃO, 2011). Atores que buscam valorizar as velhas atividades e promover outras que sejam capazes de explorar as potencialidades do território (CRISTÓVÃO, 2011).

Para Cristóvão et. al. (2005, p.159), “um grande número de organizações de tipos diferentes intervém, hoje, nas áreas rurais mesmo no chamado "rural profundo", procurando implementar estratégias de desenvolvimento que asseguram a revitalização do território". Assim, "a abordagem territorial aparece como um enfoque que permite compreender o papel do contexto e do espaço social nas escalas local e regional como fator de desenvolvimento rural" (OLIVEIRA; HESPANHOL, 2001, p.9).

Para entender o desenvolvimento rural, primeiramente abordamos o conceito de desenvolvimento. Para Amaro (2003), este conceito tem sido nos últimos anos, um dos mais importantes e polêmicos, presentes em diversas áreas disciplinares e em diálogos interdisciplinares, motivando mudanças no espaço e sociedade.

O conceito de desenvolvimento "está particularmente ligada à ideia de dinâmica, de mudança centrada no homem e nas suas estruturas" (LOPES, 2012, p. 21). Esta mudança em muitas discussões foi vista no âmbito econômico, comparando capital e tecnologias.

Entretanto, o desenvolvimento deve ser pensado como um processo social e local, não apenas puramente econômico. Como coloca Esteva (1996), a palavra desenvolvimento consiste na realização de potencialidades no âmbito social, econômico, político e cultural de uma sociedade em perfeita sintonia com o meio ambiente e de acordo com os valores éticos. É importante salientar que existe uma perspectiva multidimensional dos conceitos de desenvolvimento e território, sendo esta multidimensionalidade composta por processos materiais e imateriais (OLIVEIRA; HESPANHOL, 2001).

Desta forma, o desenvolvimento requer avaliar muitos aspectos, entre estes econômicos, sociais, ambientais e culturais, que são próprios do entorno e dos grupos de atores envolvido no processo. De acordo com Veiga (2005), o desenvolvimento não é um dom adquirido por certos países, regiões, lugares ou grupos sociais, definido e acabado, ele é uma construção sujeita a mudanças, conflitos e diferentes representações políticas, culturais e econômicas (VEIGA, 2005).

Especificamente, quanto ao desenvolvimento rural, este está relacionado às relações sociedade e agricultura; às sinergias locais e regionais, que surgem de um processo que envolve múltiplos atores e relações; e na valorização da paisagem e ecossistema local (KAGEYAMA, 2004). 
Neste sentido, pensar no desenvolvimento rural é analisar a essência do espaço e de relações de vida do mesmo. Este conceito vem sendo muito discutido, atualmente, na Europa e no mundo (MARTINHO, 2000). Assim, o desenvolvimento rural pode ser definido como a melhoria das condições de vida das pessoas que residem nos territórios rurais, articulando os seguintes princípios: eficiência econômica, aspectos sociais e territoriais, qualidade patrimonial e ambiental, sustentabilidade e participação democrática (MARTINHO, 2000).

Para Cardoso (1993), o desenvolvimento rural envolve uma transformação das economias rurais, sendo usado o termo como uma forma de intervenção do Estado através de programas e políticas públicas. O desenvolvimento rural não remete apenas à produção e distribuição dos bens, mas aos elementos como saúde, educação e habitação, relacionando a melhoria das condições de vida das populações rurais (CARDOSO, 1993).

No entanto, ao se analisar o lado econômico do desenvolvimento rural atualmente tem-se relacionado este espaço com a diversificação das atividades, deixando no passado a visão tradicionalista do rural agrícola (PINTO, 2011). Através da diversidade de atividades é mais fácil garantir uma sustentabilidade rural e promover a valorização do local.

Nesta discussão, o realce do local na discussão do desenvolvimento permite a valorização das características específicas territoriais (históricas, culturais, relacionais), a fim de possibilitar respostas sustentáveis e inovadoras às necessidades da comunidade (GOMES, 2014). E assim,

\footnotetext{
Ao reconhecer e impulsionar a capacidade de ação dos atores locais, o desenvolvimento local possibilita a identificação e mobilização de recursos endógenos e exógenos, originando processos de transformação da realidade local, com base nos valores do "outro" desenvolvimento (GOMES, 2014, p. 7).
}

Para Queiroz (2005), o desenvolvimento deve ser pensado para além de apenas resolver os problemas imediatos - como a criação de riqueza, a melhoria da qualidade de vida das populações de um território, a manutenção de ecossistemas, etc., mas também de criar formas de estar e viver em sociedade, baseadas na solidariedade e cooperação.

Neste viés, o desenvolvimento associa-se a uma base territorial e à valorização da comunidade, através da mobilização das suas capacidades e recursos, num processo de cooperação entre pessoas e entidades (LOPES, 2012).

Ressalta Corrêa (2009), que nos últimos anos, a discussão sobre desenvolvimento passou a destacar a importância dos atores locais, gerando sinergias no território, articulada com as políticas públicas (CORRÊA, 2009). O desenvolvimento centrado em pessoas e na comunidade local permite o fortalecimento do capital 
social do território, constituindo um instrumento de poder e de práticas de dinamização econômica (CRISTÓVÃO, et. al., 2005).

No entanto, é necessário uma autonomia da população local na busca do seu próprio desenvolvimento (ROVER E HENRIQUES, 2006). Ainda, Rover e Henriques (2006) colocam que, a construção de um desenvolvimento com autonomia deriva da interação e ação coordenada das organizações sociais e também da "identificação de necessidades e interesses comuns entre diferentes atores socioeconomicamente fragilizados e a sua organização para a satisfação destas necessidades e interesses" (ROVER; HENRIQUES, 2006, p. 134).

Para isto, Pinto (2011, p. 26) diz que “A constituição de organizações cooperativas e de associações de produtores é um marco fundamental no processo de desenvolvimento". Neste sentido, surgem muitas associações que atuam como articuladoras dos interesses dos atores locais na reivindicação de políticas públicas e condições de desenvolvimento territorial. O associativismo permite "melhorar as condições de vida dos indivíduos de um determinado local, pois faz com que a troca de experiências e a convivência entre as pessoas se constituam em oportunidade de crescimento e desenvolvimento" (LEONELLO; COSAC, 2008, p. 1).

O associativismo é, então, um processo social que cria condições para o desenvolvimento, pois, conforme diz Bittencourt (2014, p. 255), "o associativismo pode ser entendido como um conjunto de pessoas que aglutinam forças e iniciativas de cooperação imbuídas em assistir as desigualdades e para a promoção do desenvolvimento local sustentável".

Segundo Sangalli, et. al. (2015) o associativismo consiste num caminho a ser percorrido por agricultores e atores territoriais, tendo em vista que "além de nortear para melhores condições econômicas e sociais, tende a materializar os mecanismos que concretizam as demandas sociais" (SANGALLI, et. al., 2015, p. 229).

Ainda, neste assunto, Gomes (2014, p. 4), discorre que,

\begin{abstract}
O associativismo é visto como uma força estratégica no quadro do desenvolvimento local que contribui para a promoção da coesão social e para a melhoria da qualidade de vida das comunidades. A abordagem ao associativismo não pode deixar de ter por referência o panorama atual de complexificação dos problemas sociais, que tem exigido a mudança de paradigmas e a experimentação de respostas inovadoras ajustadas às particularidades dos problemas e às especificidades contextuais onde estes se inserem.
\end{abstract}

Desta forma, o associativismo é importante para o desenvolvimento territorial, pois permitem que os atores dinamizem as atividades socioeconômicas, valorizem o seu contexto local, reivindiquem ações, recursos e políticas para melhorar o espaço de vivência e trabalho. 
Estas ações associativistas são corporizadas no território do vinho do Douro, Portugal, através de projetos e forças coletivas diversas que vêm promovendo o desenvolvimento local das comunidades rurais e da vitivinicultura que é a dinâmica econômica de maior dinamismo na região.

\section{Região do Douro: o rural vinhateiro}

O Douro é compreendido por uma região situada ao Norte de Portugal (Figura 1), segundo Masson (2001), a região fica situada a mais de cem quilômetros do oceano atlântico, a aproximadamente 1400 metros de altitude, sendo, portanto, uma região montanhosa que tem como elementos marcantes: o Rio Douro e a produção de vinhos, especialmente o Vinho do Porto.

Figura 1. Mapa de localização da Região do Douro, Portugal. Fonte:http://www.adegaalmeida.com.br/blog/wpcontent/uploads/2015/03/mapa-portugal1.jpg. Adaptado por: MANFIO, V. (2017).

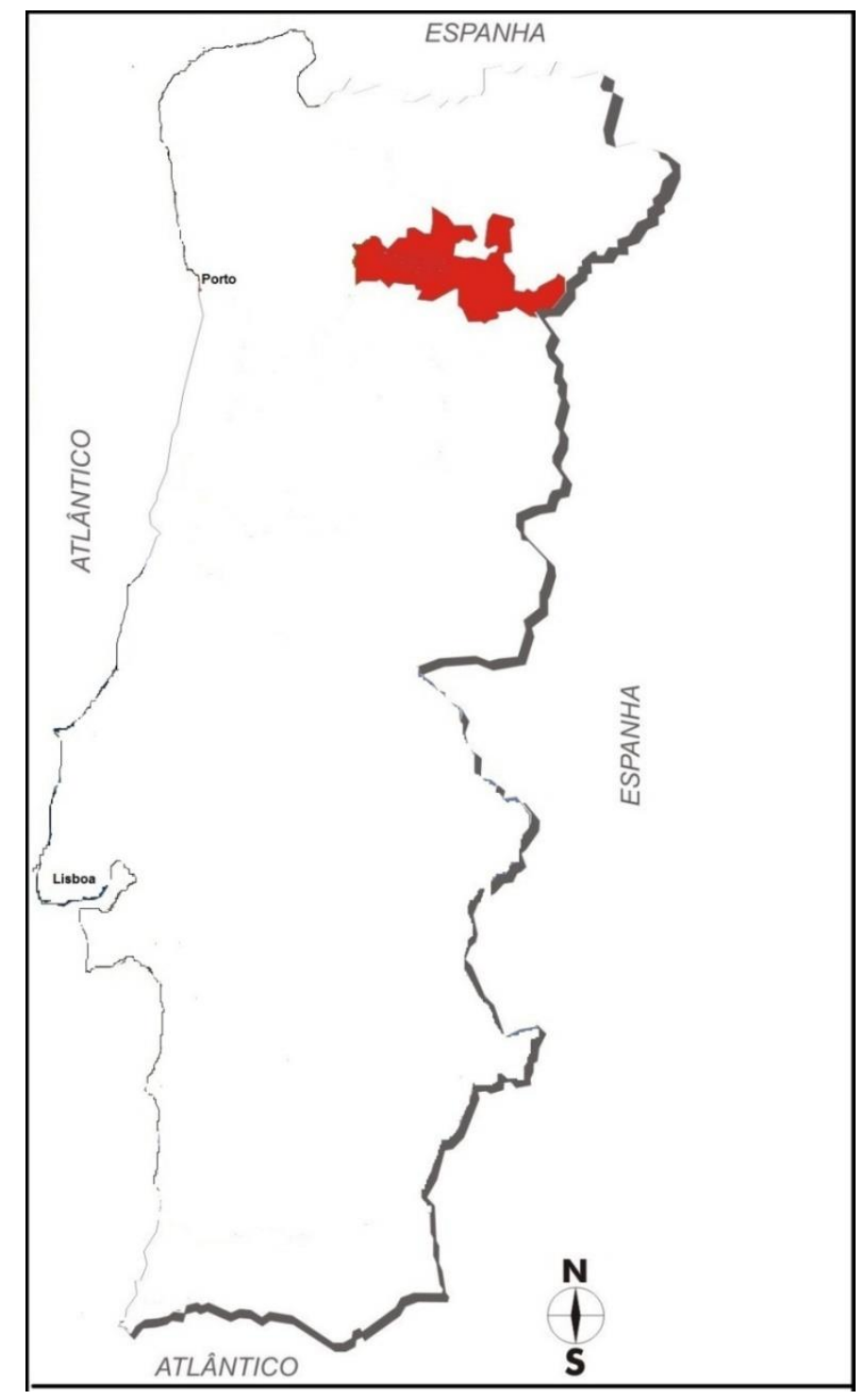


Esta região tem uma tradição histórica ligada à vitivinicultura. Segundo Carrera (2002), desde o surgimento de Portugal existem registros de vinhas junto ao Vale do Douro, sendo a expansão da vitivinicultura na região, provocada por interesses comuns de senhores, camponeses e de ações religiosas.

No entanto, a vitivinicultura enfrentou períodos de expansão e dinamismo e de retrocesso e decadência. Em um dos períodos de crise do vinho, o Marquês de Pombal, o então primeiro ministro de Portugal, criou a Região Demarcada do Douro (RDD) e a Companhia Geral da Agricultura das Vinhas do Alto Douro, a fim de organizar a vitivinicultura e estabelecer a regulamentação de técnicas, produtos e serviços (CARRERA, 2002).

Com isto, passa a existir um território do vinho no Douro com regras específicas, quanto aos aspectos ambientais (principalmente, solo, clima e relevo), aos tipos de videiras e as particularidades das uvas e aos aspectos humanos. Este território é reconhecido mundialmente pela singularidade das suas formas espaciais.

No entanto, evidencia-se que a região do Douro não apresenta as mesmas características sociais, econômicas, rurais e ambientais na sua totalidade. Por isto, a região apresenta uma subdivisão que aborda estes aspectos distintos do território. Segundo Lopes (2012), a região do Douro apresenta, devido às características de clima, solo, e condições socioeconômicas, uma sub-regionalização compreendida por três espaços: Baixo Corgo, Cima Corgo e Douro Superior (Figura 2).

Figura 2. As sub-regiões do Douro. Fonte: https://www.ivdp.pt/pagina.asp?codPag=16

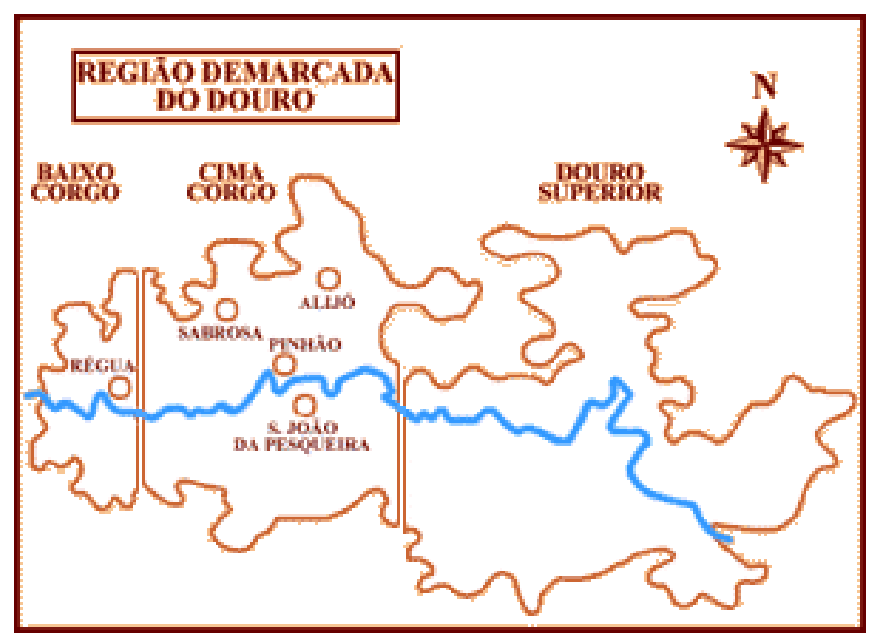

Estas três sub-regiões do Douro apresentam a história, a economia e a cultura associadas à vitivinicultura. Como destaca Ribeiro (1998), a vinha e o vinho são importantes na vida da região e particularmente no quadro socioeconômico, constituindo, ainda hoje, a principal fonte de emprego e renda da região. De forma geral, o espaço geográfico do Douro é profundamente rural com aldeias de elevados índices de envelhecimento e agricultura local em forte regressão (TIBÉRIO, et. al, 2006). 
A dependência econômica quase exclusiva do vinho origina períodos de fragilidade socioeconômica, que associados à emigração e à organização deficiente da vitivinicultura provocam declínio do desenvolvimento Douro (ASSOCIAÇÃO DOURO HISTÓRICO, 1995).

Nesta região, estão presentes municípios que são essencialmente rurais, sendo o tecido empresarial e industrial destes extremamente fracos, principalmente quando a estrutura, dimensão e dinâmica (MARTINS, 2003).

As alternativas não agrárias de emprego, locais e regionais, são muito escassas estão resumidas ao (pequeno) comércio, administração pública e construção civil, e concentram-se nos maiores centros urbanos da região (RIBEIRO, 1998). Embora, a agricultura seja a atividade dominante, ela é incapaz de prover meios de vida satisfatórios para os habitantes que nela trabalham e dela fazem seu modo de vida (RIBEIRO, 1998).

Globalmente, o Douro é uma região onde predomina o minifúndio, correspondendo à uma média de 1,17 ha por proprietário (INSTITUTO DOS VINHOS DO DOURO E DO PORTO, 2017). Segundo Duarte (2016, p. 204), "em termos de ocupação territorial, predomina a pequena produção em propriedades essencialmente familiares".

Além da pequena propriedade vitícola, existem propriedades de maiores dimensões. Conforme o Instituto dos Vinho do Douro e do Porto (2017), há três situações no Douro: a pequena propriedade familiar tradicional - sem mecanização e sem mão-de-obra assalariada no trabalho com a vinha; as propriedades intermédias, com pequenas dimensões, mas mecanizadas e com encargos com mão-de-obra assalariada; e as propriedades de dimensões superiores a cerca de 30 ha que são mecanizadas, exigem mão-de-obra assalariada (empregados temporários e permanentes com contratação de estrangeiros) e são produtoras de vinho do Porto e vinhos certificados do Douro (INSTITUTO DOS VINHOS DO DOURO E DO PORTO, 2017).

É importante dizer também que no Douro existem vários perfis de produtores e atores do mercado do vinho: os pequenos proprietários, os médios proprietários, as Adegas Cooperativas (que compram uvas dos pequenos e médios produtores e assim produzem e comercializam o vinho), as associações, as grandes propriedades vitícolas, conhecidas como quintas, e as empresas internacionais que produzem e exportam vinho como a Symington Family Estates Vinhos S.A e a Gran Cruz (França), entre outras.

Dessa forma, existe uma diversidade e complexibilidade de atores, relações e situações no Douro que marcam o território e têm implicações no desenvolvimento do mesmo. Estes atores contribuem para o desenvolvimento econômico regional, porém, uma importante fragilidade tem a ver com as assimetrias territoriais e sociais, sendo de destacar o Douro Superior onde se encontram populações envelhecidas. Diante destas dificuldades têm surgido várias associações que tratam de criar condições para o desenvolvimento na essência do Douro, a partir da valorização dos recursos regionais. 
Neste contexto, um importante ingrediente é paisagem que se desenha na maior parte da Região do Douro, marcada pelo rio Douro e seus afluentes, aldeias, quintas, casas, infraestruturas rurais, vinhas com diferentes configurações, sobretudo em terraços, a par de outras culturas agrícolas, bosques e áreas por cultivar (Figura3 e Figura 4).

Figura 3. O rural e a Paisagem da Região do Douro. Fonte: autor 1(maio de 2017)

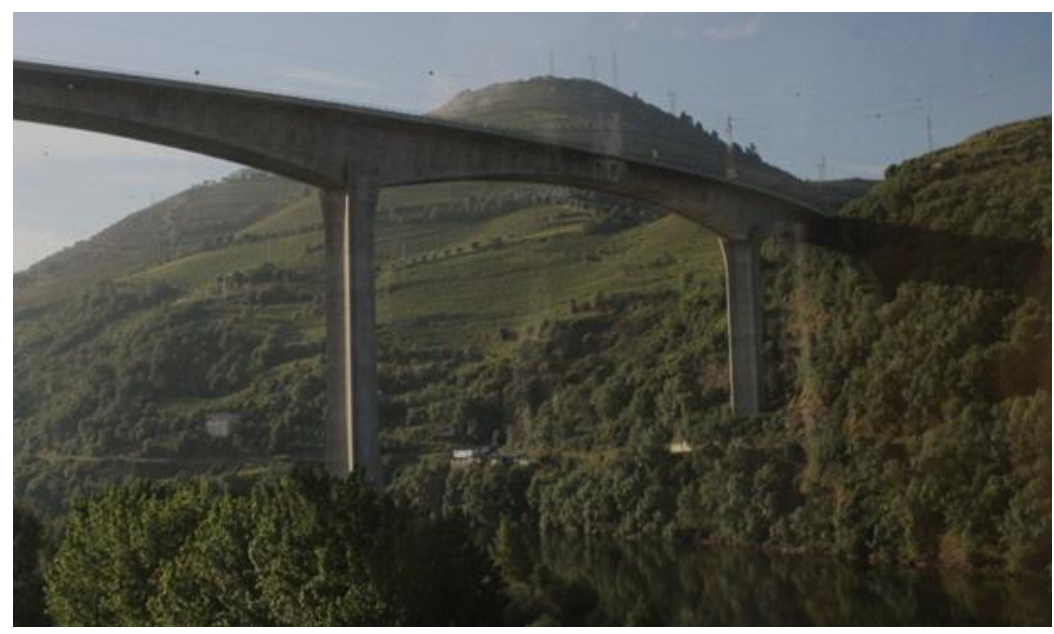

Figura 4. Paisagem rural da Região do Douro. Fonte: autor 1 (maio de 2017)

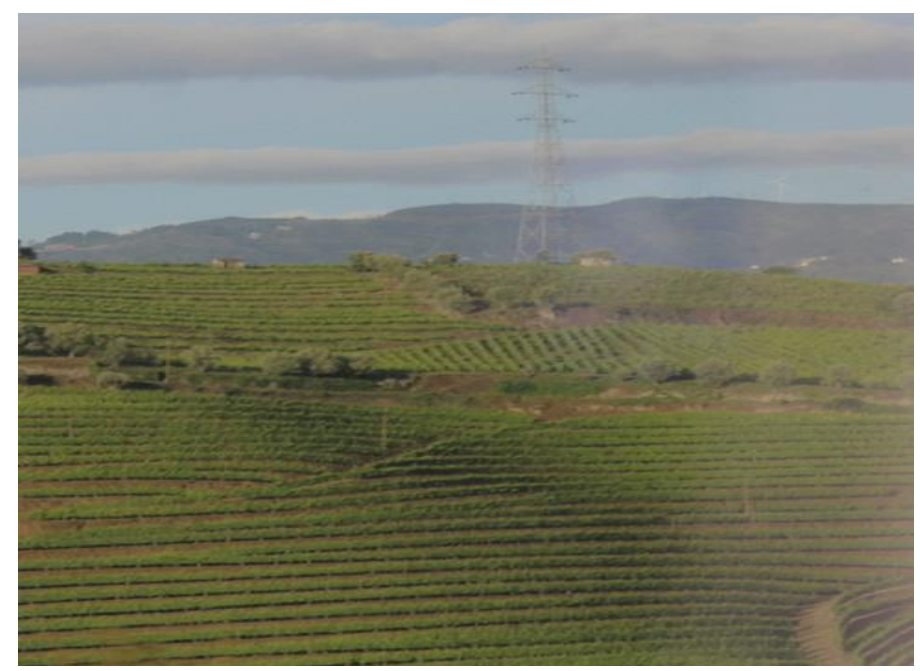

Segundo Teles (2017), a paisagem do Douro é formada por um mosaico de elementos: casebres, hortas, pomares, murros, vinhas, rios e encostas, quintas, aldeias e moratórios. Além da presença de outras culturas que estão a ganhar espaço, como as oliveiras e amendoeiras (TELES, 2017).

Uma parte do Douro, conhecida como Alto Douro Vinhateiro, foi classificada pela UNESCO com Patrimônio Mundial, enquanto "paisagem cultural, evolutiva e viva". Conforme Sousa et. al. (2009), o Alto Douro Vinhateiro, assim como a região toda é uma paisagem construída, na qual predomina a vitivinicultura 
em áreas de fortes declives, onde antigos viticultores construíram terraços onde foram plantadas vinhas e por estas razões foi reconhecida uma porção deste território, a mais expressiva como Patrimônio da Humanidade, em 2001.

Este fato tem potenciado a criação de novos serviços, a reestruturação local e o desenvolvimento rural, com o apoio de políticas e fundos vários. Ao mesmo tempo, a população e os órgãos públicos têm sido pressionados para preservar, valorizar e promover as características singulares do território.

O turismo tem sido um fator de desenvolvimento. Como referem Schneider et. al. (2006), a pluriatividade e o turismo representam uma mudança nas formas de trabalho no meio rural, sendo estratégias de reprodução das propriedades rurais. Assim, com atividades turísticas que valorizem o local, agregando novos instrumentos de trabalho e renda e modernizando os espaços rurais, é possível promover o desenvolvimento rural.

Os territórios rurais necessitam de políticas públicas visando à manutenção das suas atividades e estimulando o surgimento de novas forças econômicas. Neste sentido, as ações coletivas são mecanismos de coletar recursos públicos e privados para o investimento em estratégias de desenvolvimento local.

\section{O associativismo em Portugal}

O associativismo está presente em Portugal, muito antes do século XIX, porém é neste século que o associativismo vigora com mais ênfase no território (BITTENCOURT, 2014). No período da 1a República, o movimento associativista, em Portugal, obteve um grande incremento, assumindo as associações um papel interventivo, de valorização social (RASTEIRO; SILVA; LUZIA, 2016). Porém, no Estado Novo, as associações tiveram momentos de crises, principalmente porque passaram a ser fortemente controladas, verificando-se um novo período de crescimento na década de 1970, sobretudo após a implantação da democracia em 1974 (RASTEIRO; SILVA; LUZIA, 2016).

Na década de 1980, foram fundadas as primeiras organizações focadas nas preocupações de desenvolvimento integrado, rural, local, comunitário, social (RASTEIRO; SILVA; LUZIA, 2016). Muitas destas associações surgiram em função de programas e políticas que buscavam o desenvolvimento territorial, entre eles o Programa Ligação entre Ações de Desenvolvimento da Economia Rural (LEADER), que foi responsável pela criação de várias associações que aglutinadas ao programa, passaram a agir em prol dos territórios rurais tendo em vista o seu desenvolvimento.

Este programa foi criado pela Comissão Europeia em 1991, como um instrumento de intervenção nas comunidades rurais, agindo diretamente no desenvolvimento rural (ASSOCIAÇÃO DOURO HISTÓRICO, 1995). 
Azevedo (2006, p. 4) afirma que, "o LEADER corresponde ao conjunto de políticas de desenvolvimento rural implementado nos países membros da União Europeia, sustentado com recursos provenientes de fundos comunitários desse grupo de Estados".

Assim, tem permitido a intervenção nos territórios rurais, com o envolvimento direto de associações gestoras das estratégias locais de desenvolvimento. Para Lopes (2012), o Programa LEADER centra-se na revitalização dos espaços rurais através de iniciativas para estimular às atividades territoriais, partindo da capacidade local. Neste processo, as Associações de Desenvolvimento Local (ADL) valorizam estratégias de participação comunitária (LOPES, 2012). Pinto (2011, p. 58) sublinha que,

O incremento do associativismo foi imprescindível na projecção e coordenação das medidas implementadas pelos diversos agentes locais. Sem as ADL a gestão do LEADER dificilmente poderia ter ocorrido ao nível local e sem este contacto de maior proximidade com as realidades específicas de cada território, o programa não teria alcançado os mesmos resultados.

Segundo Rover e Henriques (2006), o Programa LEADER é considerado pela maioria dos seus interlocutores, como inovador e importante iniciativa política de desenvolvimento rural que valoriza a autonomia local e as estratégias endógenas. De acordo com Ferreira (2009, p. 6):

O LEADER tem por objetivo financiar iniciativas locais. Estas iniciativas são, em grande parte, empreendimentos de geração ou fortalecimento dos empregos rurais não agrícolas, mas também incluem a criação de infraestruturas e ações imateriais - animação e formação - que façam surgir ou fortaleçam as competências empreendedoras da população do território.

Em função do LEADER foram criadas as Associações de Desenvolvimento Local (ADL), que desenvolvem as suas ações de forma autônoma de acordo com o seu objeto, vontade dos seus associados e oportunidades existentes, através de parcerias e com a participação da comunidade (LOPES, 2012).

Estas associações permitem a aplicação nos territórios de uma ação integrada entre comunidade, recursos, entidades e empresas (LOPES, 2012). Ademais, David, Abreu e Pinheiro (2010, p. 3) mencionam que, “as ADL são parceiras privilegiadas das novas estratégias econômicas assentes no turismo e na dinamização das economias locais, em substituição das anteriores estratégias, assentes no paradigma do mercado de capitais".

Ainda, David, Abreu e Pinheiro (2010, p.19) destacam que,

As $A D L$, em conjunto com outros parceiros locais, posicionam-se estrategicamente para apoiar o turismo em espaço rural, o qual, para além de ser organizado e gerido pela população rural, integrandoa, deve revitalizar as economias locais e promover a utilização sustentável dos recursos.

É necessário abordar que, principalmente no caso do Programa LEADER, para conseguir recursos financeiros, existe uma exigência de limite de área de atuação das associações (que compreende a habitantes 
e território), pois o programa destina-se a tender pequenos projetos e comunidades locais. Dessa forma, no Douro atuam três ADLs cada com seu território e a sua realidade.

Não são apenas as ADLs que são responsáveis por dinamizar iniciativas para o desenvolvimento rural. Assim, atualmente, no território português, estão presentes diferentes tipos de associações deste as mais específicas, ou seja, de grupos de empresários em busca de novas condições de desenvolvimento, até as associações comunitárias e de valorização do local.

Estas associações atuais não têm os mesmos desafios que as antigas associações que surgiram em séculos passados no mundo. Para Rasteiro, Silva e Luzia (2016), o associativismo no séc. XXI tem desafios novos e inéditos, efeitos de uma crise que atinge os povos por todo mundo, não só ao nível econômico e financeiro, mas também cultural e social.

Os problemas econômicos que afetam os países, a imigração, o envelhecimento da população e a perda de uma identidade cultural de algumas comunidades são alguns dos problemas que precisam ser enfrentados e superados para o desenvolvimento e que contam com o auxílio de associações. Assim como acontece na região do Douro, onde o associativismo é uma ferramenta para a implantação de políticas, a busca por autonomia e desenvolvimento.

\section{As ações associativistas da região do Douro}

Na região do Douro operam associações de caráter social, econômico e cultural. Estas associações são movidas a construir novos caminhos para o desenvolvimento, através da parceria com atores, comunidade e instituições locais. Entre as associações que fazem parte desta estratégia de desenvolvimento local destacamse: a Associação Douro Histórico, a Associação Beira do Douro e a Associação Douro Superior (Associações de Desenvolvimento Local), a Associação para o Desenvolvimento da Viticultura Duriense (ADVID), a Associação dos Empresários Turísticos do Douro e Trás-os-Montes e a Douro Generation - Associação de Desenvolvimento (DG - AD).

\section{As Associações de Desenvolvimento Local}

As Associações de Desenvolvimento Local do Douro participam do processo de desenvolvimento do território rural, uma área de vitivinicultura que apresenta problemas de população envelhecida e em decréscimo. Assim, através de ações voltadas para o turismo rural, a sustentabilidade ambiental, a revitalização e a manutenção de espaços públicos e culturais, a organização de eventos culturais, a 
transformação de produtos locais em mercadorias de consumo, entre outras, instituem novas oportunidades para o desenvolvimento local e a superação dos problemas regionais.

Estas associações são compostas por representantes da comunidade local e entidades públicas e privadas, tendo um caráter de associação privada sem fins lucrativos, estando voltadas para atrair e gerir recursos e também para mediar os investimentos de programas no cenário local.

\section{Associação Douro Histórico}

A Associação Douro Histórico (ADH) foi criada em 1991 e desde então vem realizando vários projetos no âmbito da revitalização e criação de serviços locais. Esta associação abrange o território compreendido por Vila Real, Murça, Sabrosa, Alijó, São João da Pesqueira, Tabuaço, Armamar, Peso da Régua, Mesão Frio e Santa Marta de Penaguião (ASSOCIAÇÃO DOURO HISTÓRICO, 2017), área que se situa nas sub-regiões do Baixo Corgo e Cima Corgo.

No que tange os projetos e atividades desenvolvidos pela associação, é importante destacar: a revitalização e valorização da Serra Preta - patrimônio do Douro -, a recuperação e ampliação da cozinha da Santa Casa de Misericórdia de Peso da Régua e do restaurante LBV de Pinhão, para promover a gastronomia regional, e os projetos de reconversão dos olivais em Murça, Tabuaço e São João da Pesqueira, a criação de uma Casa de Campo em Vila Seca de Poiares, em Peso da Régua, a partir da recuperação de um antigo edifício, a recuperação da Igreja Paroquial de Fontelo, a publicação de um livro sobre Pinhão e a elaboração de uma campanha promocional dos vinhos do Douro (ASSOCIAÇÃO DOURO HISTÓRICO, 2017).

O Programa Palmus - Partilhar Alijó, Murça e Sabrosa, também promovido pela ADH, tem como finalidade promover a inclusão social de forma multisetorial e integrada, agregando os aspectos de emprego, formação, qualificação, intervenção familiar, acessibilidade e informação (ASSOCIAÇÃO DOURO HISTÓRICO, 2017), sendo um programa importante para a dinâmica social do território duriense.

Diante disso, observa-se que as vertentes de atuação da Associação visam atender questões sociais, educacionais, econômicas, turísticas e de serviços, para melhorar as condições locais para vivência da comunidade e dos turistas.

\section{Associação Beira do Douro}

A Associação Beira do Douro foi criada em 1995, também atendendo a filosofia do LEADER e trabalhando em prol da revitalização e valorização do local para o desenvolvimento do Douro. 
O território de atuação da Associação Beira do Douro consiste nos conselhos de: Armamar, Lamego, Moimenta da Beira, Penedono, São João da Pesqueira, Sernancelhe, Tabuaço e Tarouca (ASSOCIAÇÃO BEIRA DOURO, 2017).

Tem desenvolvido iniciativas no sentido de valorizar o patrimônio, criando roteiros que envolvam a arquitetura e arte medieval e projetos de elaboração e divulgação de produtos locais para o comércio turístico (ASSOCIAÇÃO BEIRA DO DOURO, 2017).

No tocante ao projeto de Arte Medieval, temos não apenas de divulgação, mas também a criação de produtos e atividades de merchandising associados aos roteiros medievais, como as réplicas em barro dos monumentos que integram os itinerários turístico-culturais (a Igreja de Nossa Senhora de Cárquere, Castelo de Penedono, Convento de Tarouca ou Sé de Lamego), contando com uma parceria do atelier cerâmico Lalinus, apoiado pelo programa LEADER (LIMÃO, 2008).

Outra dinâmica importante da associação é a criação de um calendário de atividades para divulgação turística da região, valorizando os eventos regionais, principalmente ligados à história (ASSOCIAÇÃO BEIRA DO DOURO, 2017).

Em resumo, a associação intervém na comunidade criando estratégias e atividades que produzem renda e criam empregos, e divulgando o Douro como região turística, vinícola e histórica, para assim proporcionar um desenvolvimento endógeno.

\section{Associação Douro Superior}

A Associação Douro Superior foi fundada em 1994 com objetivo de valorização dos artefatos locais, a promoção de eventos turísticos e a revitalização dos espaços (ASSOCIAÇÃO DOURO SUPERIOR, 2017).

A área de atuação dessa associação compreende os municípios de Vila Nova de Foz Côa, Torre de Moncorvo, Feixo de Espada à Cinta e Mogadouro (ASSOCIAÇÃO DOURO SUPERIOR, 2017), todos situados na sub-região do Douro Superior.

Dentre os projetos desenvolvidos destacam-se a animação e divulgação do Douro Superior para os turistas, envolvendo passeios de barco pelo rio Douro, visitas a museus e às gravuras rupestres do Vale do Côa, assim como a criação de página na web (PROJETOS LEADER NORTE, 2017). Outro projeto da responsabilidade da Douro Superior foi a "Revitalização de Pombais" do Parque Natural do Douro Internacional, patrimônio rural com grande valor (ASSOCIAÇÃO DOURO SUPERIOR, 2017). 
Assim, a Douro Superior é uma associação que busca criar condições de desenvolvimento na área do Douro Superior, promovendo projetos comunitários através de parcerias com empresas e instituições e mobilizando recursos públicos de programas de desenvolvimento rural e enoturismo.

Associação para o Desenvolvimento da Viticultura Duriense

A ADVID é uma associação que intervém no desenvolvimento regional da vitivinicultura, principalmente no sentido de estabelecer novas técnicas e promover pesquisas na área da vinha e dos vinhos. Para Alves et. al. (1999), a ADVID não busca apenas suprir as necessidades dos associados com consultorias, mas sim, de produzir conhecimentos que possam ser utilizados e incorporados nas tecnologias de produção de cada um dos associados.

As ações da ADVID envolvem a assistência técnica, adaptação de métodos de produção sustentáveis, estudos de implantação da vinha (analisando questões econômicas e impactos socioambientais), identificação de castas desconhecidas pelos associados, apoio relativo à aplicação de produtos fitossanitários, bem como o monitoramento do estado hídrico das videiras, realização de ensaios de experimentos de controle de pragas, fornecendo também previsões climáticas através de parceria com empresas de meteorologia e na elaboração de candidatura de projetos em âmbito regional, nacional e internacional (ADVID, 2015).

A ADVID tem um caráter diferente das demais associações do estudo, principalmente por destinar-se a pesquisa da vitivinicultura, enquanto as outras associações trabalham com o objetivo de promover o desenvolvimento local, sobretudo a diversificação da economia local. Mas esta diferença é essencial para a continuidade do desenvolvimento da região do Douro, com a melhoria das condições de vitivinicultura e enologia, conforme coloca Correia (2015, p. 13),

O contributo da vitivinicultura para o processo de desenvolvimento regional e local depende muito da sua vitalidade como atividade econômica e, por outro lado, da sua participação no desenvolvimento de outras atividades complementares.

Existe a necessidade de desenvolver a viticultura para que a região possa seguir produzindo vinhos de alta qualidade e empregando pessoas em serviços agregados a vitivinicultura. Em uma região vitícola, a ampliação de técnicas e conhecimento torna-se primordial para o desenvolvimento territorial, especialmente do meio rural.

A ADVID representa uma associação responsável pelo desenvolvimento regional da vitivinicultura, principalmente no sentido de estabelecer novas técnicas e promover pesquisas na área dos vinhos. Para Alves et. al. (1999) a ADVID não busca apenas suprir as necessidades dos associados com consultorias, mas sim, de 
produzir documentos que vem sendo utilizados e incorporados nas tecnologias de produção de cada um dos associados.

As ações da ADVID envolvem a assistência técnica, adaptação de métodos de produção sustentáveis, estudos de implantação da vinha (analisando questões e impactos socioambientais), identificação de castas desconhecidas pelos associados, apoio de aplicação de produtos fitossanitários e fito farmacêuticos, bem como o monitoramento do estado hídrico das videiras, realização de ensaios de experimentos de controle de pragas, fornecendo também previsões climáticas através de parceria com empresas de meteorologia e na elaboração de candidatura de projetos em âmbito regional, nacional e internacional (ADVID, 2015).

A ADVID tem um caráter diferente das demais associações do estudo, principalmente por destinar-se a pesquisa da vitivinicultura, enquanto as outras associações trabalham com o objetivo de promover o desenvolvimento local, a comercialização de vinhos e o turismo. Mas esta diferença é essencial para a continuidade do desenvolvimento da região do Douro, com a melhoria das condições de vitivinicultura e enologia, conforme coloca Correia (2015, p. 13)

O contributo da vitivinicultura para o processo de desenvolvimento regional e local depende muito da sua vitalidade como atividade econômica e, por outro lado, da sua participação no desenvolvimento de outras atividades complementares.

Existe a necessidade de desenvolver a viticultura para que a região possa seguir produzindo bons vinhos e empregando pessoas em serviços agregados a vitivinicultura. Em uma região vitícola, a ampliação de técnicas e conhecimento torna-se primordial para o desenvolvimento territorial, especialmente do meio rural.

Associação dos Empresários turísticos do Douro e Trás-os-Montes

Para além da vitivinicultura, o Douro está também trilhando caminhos para fortalecimento do turismo e, com isto, a criação de associações com propostas de vitalizar este setor é extremamente importante. Tal é o caso da AETUR que juntamente com outras instituições é responsável por criar condições para o fortalecimento das atividades turísticas ligadas a vitivinicultura e ao patrimônio histórico e cultural presentes na região do Douro. Segundo entrevistado A, "a criação da associação advém da necessidade de divulgação da região, tendo um conjunto de empresários da região investido no turismo associado ao vinho, acreditando ser a melhor forma de promover o desenvolvimento regional".

Assim, a AETUR tem promovido vários projetos e iniciativas que levam ao reconhecimento da região no exterior e também ao desenvolvimento de atividades turísticas na região. Entre os projetos destacam-se: "O Douro a volta do Mundo", o "Douro e Estrela" e "Há um rio que começa no Douro e termina no Brasil". 
Segundo a AETUR (2017), o projeto "O Douro a volta do Mundo" visa promover ações de internacionalização da economia com base na identidade duriense (modos de vida, arquivo da memória, patrimônios da humanidade e patrimônio imaterial), unindo o Douro à epopeia do navegador Fernão de Magalhães através da utilização da realidade virtual.

Outro projeto importante é o "Douro e Estrela", de coprodução com o Núcleo Empresarial da Região da Guarda (NERGA), abrangendo o Douro e a Serra da Estrela, objetivando melhorar a competitividade das empresas, especialmente as pequenas empresas do território de intervenção, através do estimulo à cooperação empresarial e da promoção da imagem do território nos mercados internacionais (DOURO \& ESTRELA, 2017).

Considerando que o Brasil é uma das principais fontes de turistas que visitam o Douro, criou-se o projeto "Há um rio que começa no Douro e termina no Brasil", para divulgação no Brasil dos circuitos turísticos que abrangem a região do Douro, desde o rio, as quintas e vinhas, à paisagem, ao patrimônio e cultura (SOUSA, 2015). Neste contexto, o entrevistado A disse que "já foram realizadas várias missões no Brasil, principalmente em São Paulo e Rio de Janeiro, para divulgação do Douro turístico, tendo como desafio impulsionar a vinda de brasileiros para a região".

Desta forma, a AETUR vem desempenhando um papel significativo na divulgação da região e na expansão do turismo regional com o objetivo de promover o desenvolvimento por vias de agregar o Douro, o vinho e o turismo.

Douro Generation - Associação de Desenvolvimento (DG-AD)

Neste processo de desenvolvimento do Douro, a divulgação e a criação de eventos são importantes para fortalecer a imagem da região, sendo este, portanto, o objetivo principal da Douro Generation - Associação de Desenvolvimento.

Neste âmbito, a DG-AD apresenta como eixos de trabalho: o desenvolvimento sustentável, o ambiente, as dinâmicas locais de regeneração, viabilidade das zonas rurais de baixa densidade (DOURO GENERATION ASSOCIAÇÃO DEDESENVOLVIMENTO, 2017). Para dar conta dos objetivos da associação, conforme entrevistado B "já foram organizadas as seguintes atividades: a) Projeto "Douro em Movimento, Aldeias com Vida", em cooperação com a Wine Villages - Associação para o Desenvolvimento da Rede de Aldeias Vinhateiras do Douro; b) Encontros de Reflexão sobre o Douro e o Património da Humanidade; c) Fórum Douro valor". 
Outros projetos também são desenvolvidos pela Associação, como a criação da Plataforma online Douro Mágico360, que permite uma inter-relação entre os turistas e o Douro, onde virtualmente as pessoas podem conhecer restaurantes, hotéis, serviços e produtos do Douro.

Estas atividades acabam por conectar o Douro ao resto do mundo, através de debates, eventos, plataformas e recursos digitais para assim proporcionar o desenvolvimento local, aumentando a viabilidade do Douro como patrimônio mundial e dinamizando a economia local.

Para Manfio (2018), o desenvolvimento do turismo na região é imprescindível para população local permanecer no Douro, assim como estratégias de diversificação econômica, tais quais: criação e revitalização de hotéis, pousadas e restaurantes e infraestruturas de deslocamento populacional, valorização e incentivo ao artesanato local contribuem para aumentar a renda e o emprego da região.

Dessa forma, observa-se através dos trabalhos de campos e análises de documentos que a região do Douro possui um tecido associativista muito distinto e ativo, que abrange a vitivinicultura, ambiente, patrimônio, turismo e desenvolvimento. Os empresários outros agentes locais, juntamente com instituições públicas e privadas, participam de vários projetos cooperativos, sendo em alguns casos participantes de mais de uma ação coletiva, a fim de promover o desenvolvimento local e empresarial.

\section{CONSIDERAÇÕES FINAIS}

O território é produzido por atores através da energia e da informação, das relações e territorialidades e da apropriação e delimitação espacial (SAQUET, 2009). Estes territórios podem ser urbanos ou rurais, cada qual com seus valores e intenções. Porém, tanto um quanto o outro carrega na sua integridade a intenção do desenvolvimento local.

O desenvolvimento local não é uma tarefa fácil, requer uma interação de instituições, relações e ações capazes de promover a qualidade de vida social, ambiental e econômica do território. Neste contexto, as associações são importantes, pois representam a busca por melhores condições de desenvolvimento e territorializam o espaço.

Este trabalho é feito por uma ou várias associações, individualmente ou em parceria. Existem territórios marcados pela atuação de uma associação, enquanto outros são marcados por várias associações e instituições que juntamente com o grupo social representam o cerne da constituição territorial. De modo geral, as associações buscam criar novas oportunidades socioeconômicas e minimizar as dificuldades locais, que na verdade são obstáculos ao progresso territorial. 
No Território do Douro constituído a partir de relações, que envolvem uma história coma vitivinicultura e atores que trabalham na constituição desta atividade e de outras fontes de desenvolvimento, valorizando a paisagem tem-se verificado a atuação de ações coletivas de associações voltadas ao desenvolvimento local.

A participação de várias associações no Douro tem promovido a autonomia à população local, valorizando o território - sua história e seus bens materiais e imateriais -, dinamizado o investimento na revitalização e construção de espaços, desenvolvido serviços e produtos que agregam valor, e estimulado a inovação científica e uso de tecnologia, a partir de pesquisas e estudos, além de criar novas atividades, como o turismo, e de ampliar os horizontes mercantis do território, ou de um produto específico, por exemplo, o vinho.

Dessa forma, na região do Douro as associações buscam atender as necessidades das comunidades e dos pequenos, médios e grandes produtores de vinhos que necessitam de impulsos para continuar a trabalhar na vitivinicultura e inserir a pluriatividade em suas propriedades, especialmente em pequenos produtores rurais, cujas condições de vida têm sido mais difíceis pela falta de população jovem e de recursos financeiros para competir no mercado do vinho, cada vez mais globalizado.

A constante formação de projetos e iniciativas é importante para que as propriedades continuem a se modernizar e valorizar ao mesmo tempo o território na sua essência de vida social e histórica, porém observase que a integração e as parcerias entre instituições podia ser mais intensa, construindo-se uma rota turística, com a formação de pessoas e melhoria e diversificação de transportes públicos, para assim atrair mais pessoas à região e com isto, aumentar a produção/comércio/renda, a fim de consolidar o desenvolvimento local.

\section{REFERÊNCIAS}

ALVES, F. et. al. O associativismo. Estudos \& Documentos: Encontros na casa da calçada - O douro em Debate atas III. [s.I.]: GEHVID e Círculo Cultural Miguel Torga, 1999.

ADVID. Associação para o Desenvolvimento da Vitivinicultura Duriense: serviços. Peso da Régua - Vila Real: ADVID, 2015. Elaborado para divulgação da associação.

ASSOCIAÇÃO DO DOURO HISTÓRICO. Portucale. In: 20 valores do Mundo Rural. Porto: Instituto de Estruturas Agrárias e Desenvolvimento rural (IEADR) e Programa de Iniciativa Comunitária (LEADER), 1995. p. 79-88.

ASSOCIAÇÃO DO DOURO HISTÓRICO. Portucale. História. Disponível em:

http://www.dourohistorico.pt/sobre_adh/index.php?action=getHistorico. Acesso em: 20 de jun. de 2017.

AETUR. Magallan World. Disponível em: http://www.magellanworld.pt/. Acesso em: 4 de maio de 2017.

AMARO, R. R. Desenvolvimento - um conceito ultrapassado ou em renovação?: Da teoria à prática e da prática à teoria. Caderno de Estudos Africanos. Lisboa. n. 4, p. 35-70. 2003.

AZEVEDO, F. F. de. Cultura e desenvolvimento rural: as experiências LEADER e PRODER na Espanha. In: ENCONTRO DE GRUPOS DE PESQUISA, II., 2006. Uberlândia - MG, Anais... Uberlândia - MG, 20 a 22 de jun. de 2006. Disponível em: http://w3.ufsm.br/engrup/iiengrup/pdf/t22.pdf. Acesso em: 26 de jun. de 2017. 
BEIRA DO DOURO. Associação: território e história. Disponível em: http://www.beiradouro.pt/. Acesso em: 22 de maio de 2017.

BITTENCOURT, B. de L. Políticas de desenvolvimento local sustentável e o terceiro setor: estudo de caso na região de Aveiro. 2014. 716f. Tese (Doutorado em Sociologia Econômica e das Organizações) - Universidade de Lisboa, 2014.

CARDOSO, F. J. Gestão e desenvolvimento rural: Moçambique no contexto da África sub-sahariana. Lisboa: Fim de Século Edições Ltda, 1993.

CORREIA, A. A Vitivinicultura na região do Alentejo: A passagem de um setor tradicional para um setor inovador o caso da subregião vitivinícola de Reguengos de Monsaraz. 2015. 132f. Dissertação (Mestre em Gestão do Turismo) - Universidade Nova de Lisboa: Faculdade de Ciências Sociais e humanas, Lisboa, 2015.

CARRERA, C. Vinho do Porto e a região do Douro: História da primeira região demarcada. Sintra-Portugal: Colares, 2002.

CORRÊA, V. P. Desenvolvimento territorial e a implantação de políticas públicas brasileiras vinculadas a esta perspectiva. Boletim Regional, Urbano e ambiental. Brasília: Instituto de Pesquisa Econômica Aplicada. n. 3, p.23-37. 2009.

CRISTÓVÃO, A. et. al. Dinâmicas organizacionais e desenvolvimento local no Douro-Duero. In: ROSA, E. (coord.). A Douro-Duero séc. XXI: Aproveitamento e Valorização dos Recursos. Vila Real: UTAD, p. 159-168. 2005.

CRISTÓVÃO, A. Aç̧ão coletiva e turismo em espaço rural: as rotas do vinho e do azeite no Douro e Trás-Os-Montes, Portugal. In: SOUZA, M. de; ESTEBÃO, I. (orgs.). Turismo Rural: Iniciativas e inovações. Porto Alegre: Ed. da UFRGS, 2011. p. 101-141.

DAVID, F.; ABREU, R.; PINHEIRO, O. Importância das Associações de Desenvolvimento Local na economia do turismo. In: JIMÉNEZ, M. S.; MARTÍ, T. T. (coord.). Anales de Economía Aplicada. [s. I]: Delta publicações, n. XXIV. 2010. Disponível em: http://bdigital.ipg.pt/dspace/handle/10314/2672. Acesso em: 20 de jun. de 2017.

DOURO GENERATION - ASSOCIAÇÃO DE DESENVOLVIMENTO. História e atividades. Disponível em: http://dourogeneration.com/quem-somos/. Acesso em: 29 de abr. 2017.

DOURO \& ESTRELA. Projeto. Disponível em: http://projeto.douroestrela.com/douro_estrela/. Acesso em: 3 de maio de 2017.

DOURO SUPERIOR. Estratégia de Desenvolvimento local Douro Superior. Disponível em:

http://dourosuperior.pt/documentos/Estrat\%C3\%A9gia_de_Desenvolvimento_Local.pdf. Acesso em: 29 de maio de 2017.

DUARTE, T. S. A identidade territorial como estratégia de planejamento do território rural: interfaces entre Vale dos Vinhedos e o Alto Douro Vinhateiro. 2016. 380f. Tese (Doutorado em Ciências) - Universidade de São Paulo. São Paulo: Faculdade de Filosofia, Letras e ciências, 2016.

ESTEVA, G. Desenvolvimento. In: SACHS, W. et. al. (editor). Dicionário de Desenvolvimento: Guia para o Conhecimento como Poder. Petrópolis, RJ: Vozes, 2000.

FERREIRA, J. Do desenvolvimento local ao desenvolvimento territorial. In: ENCONTRO NACIONAL DE GEOGRAFIA AGRÁRIA, XIX, 2009, São Paulo. Comunicações... São Paulo, 2009, p. 1-21.

GOMES, C. S. T. Desenvolvimento local, governança colaborativa e associativismo: dinâmicas de mobilização para ações no contexto do município de Peniche. 2014. 62f. (Mestrado em Sociologia) - Instituto Universitário de Lisboa, Lisboa, 2014.

HAESBAERT, R. Dos múltiplos Territórios à Multiterritorialidade. In: HEIDRICH, A. et al. (Org.). A emergência da multiterritorialidade: a ressignificação da relação do humano com o espaço. Porto Alegre: Ed. da ULBRA: Ed. da UFRGS, 2008. p. 19-36.

INSTITUTO DOS VINHOS DO DOURO E DO PORTO. Manual de boas práticas vitícolas: Região Demarcada do Douro. Disponível em: http://www.ivdp.pt/pt/docs/SUVIDUR/MBP_(vs_integral).pdf. Acesso em: 30 de jun. de 2017.

KAGEYAMA, A. Desenvolvimento rural: conceito e medida. Cadernos de Ciência e tecnologia. Brasília. v. 21, n. 3, set./dez. 2004.

LEONELLO, J. C.; COSAC, C. M. D. O associativismo como alternativa de desenvolvimento local e sustentabilidade social. In: SEMINÁRIO DO TRABALHO: Trabalho, Economia e Educação no século XXI, VI., 2008, Marília. Comunicações... Marília, 2008.

LIMÃO, J. Turismo e cultura no Douro Sul. Jornal de Animação da Rede Portuguesa Leader +. Lisboa. Serie II, n. 50, 2008 , p. 6-7. Disponível em: www.leader.pt. Acesso em: 9 de maio de 2017.

LOPES J. M. A. (Re) inverção do local: o papel das associações de desenvolvimento local e do programa LEADER. 2012. 160f. Dissertação (Mestrado em Sociologia) - Universidade de Coimbra, Coimbra, 2012.

Manfio, V. Vitivinicultura e associativismo: a dinâmica da Associação Vinhos da Campanha na formação de um território no Rio Grande do Sul, Brasil. 2018. 254f. Tese (Doutorado em Geografia) - Universidade Federal do Rio Grande do Sul, Porto Alegre, 2018. 
MASSON, C. Douro terra do Porto. Paris: Edições LPM, 2001.

MARTINHO, V. J. P. Reflexões sobre o desenvolvimento rural nacional. Millenium. Viseu: Instituto Politécnico de Viseu, n.19, jun. 2000.

MARTINS, C. A. Turismo em zonas rurais: oportunidades para a região de Trás-Os-Montes e Alto Douro. 2003. Disponível em: https://bibliotecadigital.ipb.pt/handle/10198/2238. Acesso em: 19 de jun. de 2017.

OLIVEIRA, A. R. de; HESPANHOL, A. N. O associativismo e o desenvolvimento territorial rural do Pontal do Paranapanema-SP. In: ENCONTRO DOS GRUPOS DE PESQUISA, III., 2007, Porto Alegre. Comunicações... Porto Alegre, 30 de julho a 1 de agosto de 2007. p. 1-13.

PARENTE, S. C. Adegas cooperativas na Região Demarcada dos Vinhos Verdes - Qualidade e estratégias comerciais. In: COLÓQUIOS HISPANO-PORTUGUESES DE ESTUDOS RURAIS (CHPER) VI., 2001. Santiago de Compostela - ES. Comunicações... Santiago de Compostela - ES, 2001.

PINTO, A. C. dos S. Pensar os territórios rurais: paisagem, planejamento e desenvolvimento em Sever do Vouga. 2011. 156f. Dissertação (Mestrado em Geografia Humana) - Universidade de Coimbra: Faculdade de Letras, Coimbra, 2011.

PROGRAMA LEADER NORTE. Projetos. Disponível em: http://www.minhaterra.pt/IMG/pdf/3_PROJETOS_LEADER_NORTE-2.pdf. Acesso em: 15 de jun. de 2017.

QUEIROZ, P. G. de. Turismo rural e desenvolvimento localna agricultura familiar. In: CONGRESSO DA SOBER. XLIII, 2005, Ribeirão Preto. Comunicações... Ribeirão Preto, 24 a 27 de jul. 2005.

RASTEIRO, O. SILVA, M.R.; LUZIA, A. Almada, o desenvolvimento local e o associativismo. 2006. Disponível em: https://pt.linkedin.com/pulse/o-associatismo-e-desenvolvimento-local-domingos-rasteiro. Acesso em: 20 de jul. de 2017.

REBELO, J. Economias de escala e de gama nas adegas cooperativas da Região Demarcada do Douro. Estudos de Economia. Lisboa: Universidade de Lisboa, v. XIII, n. 4, jul-set. de 1993.

REBELO, J. F.; SILVA, A. J. F. C. As cooperativas vitivinícolas no contexto económico da região demarcada do Douro. Douro - Estudo \& Documentos. v. 1, n. 2, p. 249-263. 1996.

RIBEIRO, M. Turismo rural e desenvolvimento na região do Douro - Processos e (alguns) resultados da evolução recente do sector. Douro - Estudos \& Documentos. v. III, n.6, 2 sem., p. 25-49. 1998.

ROVER, O. J.; HENRIQUES, M. A. A gestão democrática em debate: o programa LEADER e a sua relação com a sociedade civil local. Revista Crítica de Ciências Sociais. Coimbra: Universidade de Coimbra, n.75, p. 117-137, out. de 2006.

SANGALLI, A. R. et. al. Associativismo na agricultura familiar: contribuições para o estudo do desenvolvimento no assentamento rural Lagoa Grande, em Dourados (MS), Brasil. Organizações rurais e agroindustriais, Lavras, v. 17, n. 2, p. 225-238, 2015.

SAQUET, M. A. “O Território: diferentes interpretações na literatura italiana In: RIBAS, A. D.; SPOSITO E. S.; SAQUET, M. A. (orgs). Território e desenvolvimento: diferentes abordagens. Francisco Beltrão: Unioeste, 2004.

SAQUET, M. A. Por uma abordagem territorial. In: SAQUET, M. A.; SPOSITO, E. S. (org.). Territórios e territorialidades: teorias, processos e conflitos. São Paulo: Expressão Popular, 2009, p. 73-94.

SCHNEIDER, S. et. al. A pluriatividade e as condições de vida dos agricultores familiares do Rio Grande do Sul. In: SCHNEIDER, S. (org.). A diversidade da agricultura familiar. Porto Alegre: Ed. da UFRGS, 2006, p. 137-165.

SOUSA, M.; et. al. Douro Patrimônio Mundial Preservação e Formas de Armação do Terrenonuma paisagem evolutiva e viva. In: CONGRESSO INTERNACIONAL DOS VINHOS DO DÃO, I., Viseu , 2009. Comunicações... Viseu. 3 a 6 de Jun. de 2009.

SOUSA, T.F. P. de. O turismo Brasileiro no Porto: proposta de roteiro histórico -culturais representativos da ligação entre o Porto e o Brasil. 303f. 2015. Dissertação (Mestrado em Turismo) - Universidade do Porto: Faculdade de Letras, 2015.

TELES, H. Alto Douro Vinhateiro. In: WORLD GENERATION WEEK: ENCONTRO INTERNACIONAL DOS PATRIMÔNIOS MUNDIAIS DA UNESCO, 2017, Lamego/Vila Real, Portugal. Comunicações... Lamego/Vila Real: Douro Generation - Associação de desenvolvimento, 2017.

TIBÉRIO, M. L. et. al. Microproduções agrícolas e desenvolvimento local no Douro - Duero. In: ROSA, E. (coord.). A douro / Duero séc. XXI: aproveitamento e valorização dos recursos. Vila Real: UTAD, 2006. p. 11-20.

VEIGA, J. F. F. da. Território e desenvolvimento local. Oeiras - Portugal: Celta Editora, 2005. 